\title{
¡Vamos a lo central! \\ Una propuesta pastoral
}

“¿El vino nuevo, en vasijas nuevas!” (Marcos 3, 22)

Alberto Henriques, $s d b^{*}$

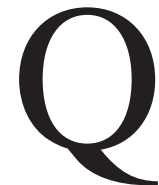

ueremos hilvanar algunas reflexiones que brotan de la práctica pastoral y de la meditación sobre la Iglesia local y universal, tan querida, pero tan sacudida por las situaciones que estamos viviendo en este comienzo del nuevo siglo. Queremos mirar al futuro con esperanza y desde una visión creyente y con corazón amante, tomar conciencia de los logros y límites que atraviesan nuestro ser y la práctica cristiana católica, para vislumbrar los caminos que el Señor nos propone en la historia hoy.

\section{Cambio de época}

Este nuevo siglo nos hace tomar conciencia de situaciones críticas y problemáticas que afectan a nuestra vida cristiana personal, comunitaria e institucional. Sentimos como un cierto desasosiego y malestar ante el mundo que vivimos y las respuestas que estamos dando y proponiendo. En efecto, nos encontramos con una crisis generalizada de costumbres, creencias, normas, que alteran a la sociedad y que sacuden a las diversas Iglesias, incluyendo nuestra Iglesia Católica.

El marco general de la globalización que acepta la interconexión e interdependencia de todos los países y pueblos hace que detectemos situaciones profundamente asimétricas en las relaciones entre los países más acomodados del planeta y los países deprimidos en su economía, donde a su vez se da una gradación inmensa de diversas situaciones de

* Párroco del Santuario de María Auxiliadora en la ciudad de Cuenca-Ecuador. 
empobrecimiento. Se trata, pues, de una globalización que excluye a las mayorías de pobres de los beneficios de la economía y de la cultura, donde el polo opulento impone las reglas de funcionamiento en su propio beneficio. La situación es de tal desigualdad, que comienzan a darse indicios de confrontaciones entre los grupos ricos y pobres de la Tierra, que pueden llevar a una situación de oposición cada vez más activa.

Los organismos oficiales internacionales brindan abundantes estadísticas de las inmensas asimetrías que se dan en todo orden, sin embargo, las respuestas y las propuestas tienen una ineficacia tan grande, que hacen ver el carácter hipócrita de los análisis efectuados. Hay muchos estudios, demasiados planes, y ninguna solución real y cualitativa de cambio.

Por otra parte, los pueblos excluidos y explotados por muchísimos caminos de acumulación en beneficio del mundo rico, continúan su lucha por subsistir, resisten desde su pobreza y, de una u otra forma, su existencia es una protesta elocuente de la inhumanidad de condiciones que se viven en todas las partes del planeta, unos porque se aprovechan, y otros porque son manipulados y marginados de manera cruel. Fundamentalmente el mecanismo de la deuda internacional es una de las cadenas con las que el mundo globalizador se impone para obtener riquezas que le beneficien sumiendo en más necesidad y en condiciones inhumanas a los pobres de la Tierra. Pero el problema no es solamente económico, sino que abarca la totalidad de aspectos de la vida humana, donde la economía tiene un alto ingrediente condicionante. En efecto, la realidad humana se desarrolla también dentro de una serie de parámetros culturales, sociales, políticos, religiosos, que indican la complejidad de la vida, que no puede contentarse con soluciones meramente técnicas, donde las personas somos un ingrediente más del problema.

Por otra parte, desde el ángulo socio-cultural y religioso, se puede detectar que la crisis influye en la manera de pensar y de actuar de muchas personas. De hecho, el secularismo que prescinde de Dios, un individualismo que busca su propio beneficio y el afán de placer exacerbado por la sexualización de la sociedad, provocan condiciones contrarias a la vivencia coherente del Evangelio. En este contexto, la crisis que estamos viviendo a nivel amplio, merece también soluciones radicales que vayan a la raíz de las situaciones, sin quedarse en soluciones parciales y sectorizadas. Dentro de este panorama amplio y complejo, que no entramos a analizarlo dentro de su particularidad analítica, que excede a 
nuestros propósitos, se insertan las Iglesias, los creyentes y el mundo religioso simbólico.

\section{La Iglesia confrontada por los cambios}

Nos referimos fundamentalmente a la Iglesia Católica, si bien, en gran medida, muchas cosas que se dirán, también se aplican a las otras Iglesias históricas y a muchos movimientos religiosos. En forma general, podemos decir que la Iglesia como institución se mueve dentro de los parámetros de la sociedad establecida con sus grandes contradicciones. La Iglesia reclama y exige por medio de sus pastores, pero dentro de la misma dinámica tolerada por la sociedad, que vive un inmenso desorden. Con el paso de la historia, paulatinamente nuestra Iglesia ha construido un frondoso sistema dogmático, moral, litúrgico, jurídico, que se sitúa aún dentro de los rezagos de la época de absorción de la Iglesia por parte de la sociedad política y civil. La libertad de la Iglesia se conjuga dentro de las libertades que permite el Estado neoliberal. Aún más, una buena porción del funcionamiento de la Iglesia está dentro de los cánones aceptados y apoyados por los estados liberales de derecho, dentro de su fase superior de interconexión. La acumulación de capitales de muchas Iglesias pone en entredicho la preocupación social por los pobres y por el cambio social. Ha sido altamente llamativa la noticia de la Iglesia norteamericana, por ejemplo, que se propone en Boston arreglar las cuentas por demandas vinculadas con la pedofilia del clero poniendo a disposición 82 millones de dólares. Hay la impresión de que la Iglesia está acentuando en su práctica cotidiana los aspectos administrativos, con predominio sobre los asuntos más pastorales. Las obras de asistencia social o educativa se han convertido en actuaciones que compiten con el Estado y con la sociedad civil, de modo que no afectan, sino que refuerzan la sólida estructura social preestablecida.

El pueblo cristiano se va dividiendo cada vez más ante el pluralismo de ofertas religiosas de diversas Iglesias y movimientos. Y otros cristianos van alejándose cada vez más de la Iglesia y de una práctica frecuente. Detrás de esta disgregación del pueblo cristiano que se hunde en la anomia o en la aceptación de diversos credos, se han denunciado intereses políticos exógenos que tienen el interés de debilitar el catolicismo sobre todo en América Latina. 
La secularización del ambiente pretende también privatizar el ámbito de la fe y de la Iglesia, encerrándola solamente en actividades y declaraciones que no pongan en cuestionamiento la estructuración oficial dominante. Y muchas veces los pastores y el mismo pueblo se han dejado alienar por este discurso nada cristiano, en búsqueda de una conciliación superficial que no llega hasta la profundidad de los problemas. El Evangelio ha quedado capturado dentro de las declaraciones de principios genéricos que no levantan interrogantes vitales. La teoría teológica predomina sobre las actitudes concretas y la toma de posición ante los poderes de este mundo.

Por otra parte, la Iglesia está muy condicionada por las ayudas que recibe directa o indirectamente del Estado, sea en el campo de la salud como sobre todo en el área de educación sistemática. Y esta vinculación, le quita libertad de maniobra para actuar y hablar con una mayor libertad de espíritu, que le daría más fuerza profética. En el fondo, se busca un cristianismo que no incomode a nadie, que brinde buenos consejos éticos, y que permita a la estructura eclesiástica desenvolverse sin mayores problemas.

Sin embargo, la Iglesia aún convoca masas de creyentes, que tienen diverso nivel de pertenencia y de vivencia explícita del amor cristiano. El catolicismo popular es todavía fuerte en América Latina, pero ha ido decayendo mucho en Europa, cuya población se mueve en los criterios de una posmodernidad más bien cortoplacista y de resultados tangibles.

Desde el centro de la Iglesia se ha intentado una visión de mayor convergencia y unidad, en consonancia con el deseo de orden y de claridad que propende el sistema secular, que para llegar a ello, ha pretendido impulsar políticas belicistas sobre todo desde el imperio norteamericano. La Iglesia ha tenido dificultad en impulsar cambios más globales, por lo que muchas veces se ha quedado en el discurso y en los enunciados que no tienen repercusiones históricas y prácticas. El aferrarse a la doctrina clara de la ortodoxia no ha alentado una inserción más inculturada en los diversos pueblos, ni un aliento misionero de más largo alcance. La crisis de vocaciones es un claro indicador de que la Iglesia no está presentando con mayor claridad y vivencia a Jesucristo y a su Evangelio de vida. En este contexto, los creyentes no sienten la urgencia del Dios salvador y de sus requerimientos, se repliegan dentro de sus instituciones y movimientos buscando seguridad y claridad mental, y otros ven de 
lejos al cristianismo como algo meramente secundario o accidental, porque ese Dios no es la propuesta interpelante de sus vidas.

Aún desde el campo oficial, la pastoral social se ha ido ligando siempre más a los subsidios "graciosos" que le conceden los gobiernos, las petroleras, los municipios, las ONGs, etc. Ha ido triunfando siempre más la planificación sobre la profecía, cayendo en el juego que el sistema dominante le propone. Entonces la pastoral social se va limitando cada vez a la tarea de insertar más personas excluidas dentro de la trama social establecida. La solidaridad se reviste de ribetes capitalistas y el interés de los beneficiarios se deshumaniza con el predominio del interés particular. El afán comunitario y redistributivo propio del amor cristiano se diluye ante las astutas propuestas del modelo de turno. Una vez más se cumple la afirmación del Señor, de que "los hijos de las tinieblas son más astutos que los hijos de la luz".

De todo lo dicho, vemos cómo la Iglesia en muchas de sus instancias, reflexiones y actuaciones no tiene la suficiente fuerza como para ayudar a proponer nuevos modelos ante el pueblo cristiano, que ante la ausencia de personalidades y propuestas significativas se repliega en sus prácticas de escasa evangelización o abandona y critica a la Iglesia establecida, en quien cree cada vez menos, y se siente cada vez menos involucrado.

Sin embargo, esta Iglesia, fusión de institución y de Espíritu, pecadora y santa simultáneamente, sigue siendo la querida Iglesia que va siendo guiada, de una u otra manera, por Jesús, el Señor de la historia. Aunque en los embates históricos se pueda debilitar y degradar en grande o pequeña medida su institucionalidad, sigue siendo el Cuerpo de Cristo a lo largo de los siglos. Es probable que una aguda crisis institucional ayude a vigorizar las fuerzas del Espíritu, con el surgimiento de nuevos creyentes más comprometidos, pobres y evangélicos, que permitan reflorecer un espíritu cristiano encarnado y auténtico que transparente el poder como servicio, la espiritualidad como mística y los recursos económicos como solidaridad. Estamos firmemente convencidos de que el Espíritu sigue vivo en esta Iglesia siempre necesitada de rejuvenecimiento ante las arrugas que los pecados de los creyentes le sembramos. Ello no quita la correspondencia siempre decidida y plena de muchos cristianos a los impulsos y sugerencias que el Señor sigue haciendo en esta historia que vivimos. La denuncia y la crítica no pueden caer en el fanatismo intolerante, pero tampoco se puede amordazar la libertad profética del Espíritu que quiere renovar todas las cosas. 


\section{Intentos de cambios en la Iglesia}

La época posterior al Concilio Vaticano II planteó una gran riqueza de posibilidades a la Iglesia Católica, que pasó del entusiasmo inicial al asentamiento paulatino de las transformaciones. En primer lugar, la Iglesia realizó un proceso de modernización interna, y fue paulatinamente fraguando sus relaciones con la sociedad circundante. Sin embargo, pasadas las euforias de cambios en la década de los setenta, ha vuelto a predominar un cierto marasmo y repliegue dentro de los procesos eclesiales en su relación con el mundo. Los vientos de renovación eclesial y social se fueron mitigando ante la capacidad de recomposición del sistema dominante, que asimiló el impacto de las propuestas de cambio, consolidando su afán dominador con la liquidación económica de la Europa del Este y el predominio del sistema capitalista en su nueva fase de complejidad globalizadora.

Este nuevo escenario mundial y eclesial asiste a la proliferación de muchísimos grupos dentro del catolicismo, con diferentes acentos religiosos, que no logran fraguar una mejor presencia dentro de la sociedad. En general son grupos cristianos que tienen su asidero social dentro de los grupos socialmente medios, que asimilan en mayor o menor medida a sectores populares. Podemos hacer una tipología aproximativa de los diversos grupos o tendencias eclesiales que se dan en el catolicismo organizado.

1) Ante todo, podemos encontrar la corriente de tipo oficial de la Iglesia, que coloca el acento en la declaración de principios, de doctrina, con carácter teórico, dogmático, y que en la práctica social coincide con posiciones claramente conservadoras. Ante las situaciones sociales tiene preocupaciones asistenciales e intenta evangelizar con consejos y oraciones. La estructura eclesiástica es fielmente respetada, no se proponen mayores cambios, las preocupaciones concretas se orientan hacia la defensa de la vida, pero es muy cauta en las exigencias sociales de justicia y de transformaciones. Muchas veces los grupos económicamente altos asumen esta posición con la anuencia de la jerarquía, pero también otros movimientos apostólicos menos acomodados coinciden con estas actitudes. Sus seguidores toman las actitudes cristianas privadas y la pertenencia a la Iglesia, si bien no vislumbran una transformación más global de la Iglesia y de la sociedad. 
2) Otra tendencia del catolicismo de nuestra Iglesia la podemos ubicar dentro de los movimientos de oración, que se caracterizan por ser instancias más bien "cordiales", con abundante sentimiento, y que incluyen una vivencia emocional fuerte, aun con así dichas revelaciones particulares de videntes. Se nota la búsqueda de consuelo, de alivio ante los problemas psicológicos, físicos o económicos de la vida; son amantes de las "sanaciones", y cuando emprenden acciones por los pobres desembocan en la asistencia social hacia los necesitados. Estos grupos han proliferado de manera abundante en los sectores medios de muchas partes. Tienen una fuerte huella de su origen norteamericano con signos del "pentecostalismo católico", y se alinean en esta perspectiva. Hacen bien a muchas personas, si bien no alcanzan a educar hacia un cristianismo adulto, dejando a sus seguidores en una fe que se liga a necesidades de todo tipo y no compromete de forma radical a la personalidad creyente. De todas maneras, ha sido una vertiente que liga a muchos creyentes hacia la Iglesia, sin cultivar un compromiso más profundo. En general, no logran abrirse hacia concepciones más abiertas del cristianismo y del mundo.

3) Otros grupos han aceptado la importancia de la Palabra de Dios en la vida, en la comunidad, en la Iglesia. Han asumido como central la meditación, la interiorización de la Biblia, fortaleciendo el estudio y la vivencia de la Escritura. Más que ver la realidad circundante de salvación y de pecado que se entrelaza en la historia, estos grupos han pretendido una aplicación individual de la Palabra, que debe cada uno aplicarse a sí mismo para encontrar el sentido de la existencia. Pero una cierta rigidez mental, una aplicación de la moral al ámbito personal y de la familia sin abrirse hacia una ética social, la fuerte jerarquización que conlleva hacia la sumisión y la obediencia, no permite crecer dentro de parámetros cristianos ligados al Jesús de la Buena Noticia. Una fuerte influencia del existencialismo europeo marca esta tendencia, que fue la manera burguesa positiva de responder al descalabro y a la angustia personal. Los límites hacia lo individual y las comunidades que tienden a cerrarse en sí mismas, provoca un fuerte limitante en este intento de evangelización. Sin duda, se regeneran muchas personas, se fomenta la pertenencia a la Iglesia, pero a un cierto punto las trabas que se ponen a un compromiso más abierto en el mundo lleva a un estancamiento y hasta abandono a militantes de esta postura eclesial y pastoral. 
4) También se ha abierto paso una corriente más bien secularizante ante los contenidos de la fe, que explica el mensaje cristiano quitando una visión, por decirlo, "mítica" de la Biblia. Entonces todos los acontecimientos y situaciones del mensaje revelado son despojados en general del hálito del "misterio" o de la resonancia con lo divino, para caer bajo la interpretación natural que explica todo de una manera más bien "científica", desde la ideología o desde la estructura, o desde los intereses concretos de los sectores sociales involucrados. Es una explicación más bien intelectualista desde los sectores medios de la Iglesia, y que tiene poca repercusión entre los pueblos pobres, que están muy impregnados de una experiencia religiosa con alto contenido emotivo y aun místico. Aún más, desde este ángulo, se puede impresionar a las personas por los enfoques novedosos con que se explica el mensaje, pero no lleva fácilmente a la conversión personal y comunitaria que tiene un alto ingrediente de llamado al corazón y no solo al intelecto. En esta perspectiva, pueden muy bien entrar muchos promotores del cambio social, desde la Iglesia, que insisten mucho en la organización del pueblo y en la formación con contenidos de transformación. Muchas veces las Comunidades Eclesiales de Base se unieron a esta corriente, inyectándole una dosis de catolicismo popular más sentido, pero han tenido un éxito relativo, sobre todo en épocas de democracias formales.

5) Añadamos aun, la perspectiva de la educación sistemática, que si bien puede tener un pluralismo de apariencias, sin embargo, se nutre de la misma estructura educativa y ejerce en líneas generales una función eclesial y social. En esta área pastoral se encuentra un número ingente de agentes de pastoral, religiosos (as) y laicos (as). Abarcan diferentes estratos sociales de la población: aquellos que son de elite y de sectores medios han llegado en muchas oportunidades a brindar la imagen de haberse convertido en empresas educativas rentables que han masificado la educación, han diluido el impacto del mensaje evangelizador y obtienen muy pocos frutos en la pastoral. También en los sectores populares se encuentran muchos agentes de pastoral que están cercanos al pueblo, pero que en la práctica no alcanzan a despertar un grupo significativo de apóstoles cristianos. Con frecuencia el sistema educativo se limita a insertar nuevos ciudadanos en la estructura socio-económica imperante y reproduce los criterios y ambigüedades de la ideología dominante. 
Después de todo lo dicho, se detecta que la actividad eclesial se dirige en gran medida hacia los sectores medios en las ciudades, mientras que en los campos la atención es más general, y tiene una influencia de éxitos muy relativos. Muchas veces, por desgracia, los pobres quedan al margen, o se les brinda una escasa evangelización y se convierten en objeto de ayudas sociales poco relevantes. Todavía estamos heredando una atención pastoral muy individualista centrada en la persona con sus problemas particulares. Y la vivencia comunitaria tampoco es de alto compromiso, porque en muchos grupos cristianos la comunitariedad es más verbal que real, ya que a la hora de la solidaridad concreta, hay mucho apego al propio yo y a las cosas que se poseen de manera individual.

Puede ser que esta visión de los intentos de cambio en el cuerpo eclesial en su configuración y apertura a la sociedad, nos deje un sabor agridulce porque, si bien de hecho se han dado pasos para actualizar la presencia de la Iglesia, sin embargo, nos encontramos con fuertes limitaciones a la hora de las concreciones prácticas e históricas. Diera la impresión de que la Iglesia es un pueblo de Dios tan amplio y tan complejo que se vuelve problemática la aplicación de los cambios sugeridos después del Concilio Vaticano II a fin de poner al día a la Iglesia en su relación con los nuevos tiempos que vivimos.

\section{¿Hacia dónde caminar?}

Después de los análisis que hemos efectuado, la pregunta evidente brota de manera espontánea. Como los judíos preguntaron a Pedro, nos interrogamos, "entonces, ¿qué tenemos que hacer?" (Hechos 2, 37). Por lo pronto, pensamos que no debemos quedarnos atrapados en la trama institucional de la Iglesia, que mirándola de manera realista, no podemos cambiar a corto plazo. Las estructuras establecidas en la Iglesia irán transformándose con el paso del tiempo ante la ineficacia de muchas de sus formas. En lo que se pueda, se podrá ir haciendo sugerencias, aunque probablemente no serán aceptadas por cobardía, por inseguridad o por miopía histórica ante lo que el Espíritu puede estar pidiendo a las Iglesias, como dice el Apocalipsis. No hay que acentuar tanto las tensiones dentro de la misma Iglesia, porque podemos caer en un desgaste empobrecedor y estéril; más bien, busquemos caminos más abiertos y evangélicos para seguir a Jesucristo. Proponemos algunas pistas de acción. 


\section{Dimensión de encarnación}

Ante todo, sigamos el camino recorrido por el Salvador: "el Verbo se hizo carne", que parece algo evidente, pero descubriendo las implicaciones que tuvo en Cristo, que nace de una mujer sencilla y virgen de Nazaret, queda excluido del consorcio humano, en el portal de Belén, y vive por muchos años en la zona despreciada y marginada de Galilea. Es decir, que la Iglesia está llamada a asumir este mismo recorrido, desde quienes desean asumir en serio el llamado evangélico.

Se descubre desde el comienzo en Jesús una fuerte vinculación entre Reino de Dios y pobreza, entre Evangelio y escasez de medios económicos. La afirmación de Pedro ante el tullido del Templo es programática: "Oro y plata no tengo, pero lo que tengo te lo doy; en nombre de Jesús de Nazaret, camina" (Hechos 3, 6). Y así camina la Iglesia desde sus inicios, pobre, perseguida, diseminada por el Imperio, con activa presencia de pueblo sencillo y de unos pocos de condición social más alta, que han aceptado vivir la fraternidad comunitaria.

Y es sintomático que muchas comunidades religiosas en la historia han surgido desde la penuria y desde la sencillez humilde. Los fundadores, con frecuencia, tenían sus finanzas en rojo, y no gozaban del apoyo oficial. Y en esos orígenes los carismas fundacionales atrajeron personas que participaron activamente en la consolidación de las nuevas fundaciones. Pero generalmente las congregaciones religiosas fueron adquiriendo poder económico, reconocimiento social y apoyo político, y entonces comenzaron a degradarse y a entrar en crisis, de modo que las nuevas vocaciones comenzaron a escasear. Ya lo advirtió con mucha clarividencia Don Bosco a los salesianos señalando que "cuando el dinero y las comodidades entren en la Congregación Salesiana, entonces la Congregación habrá terminado su carrera". En muchos aspectos, lo estamos ya viendo, a pesar del reconocimiento social que gozamos de manera superficial e interesada por parte de la sociedad imperante.

En este camino de evangelización, existe una trampa que teje la historia ante el desarrollo institucional: el trabajo sacrificado y generoso de muchos cristianos organizados, religiosos(as) o laicos(as), genera excedente económico, una plusvalía, que en líneas generales no se redistribuye a los pobres, sino que se reinvierte en el desarrollo institucional, que da poder, prestigio, competencia, pero que al mismo tiempo va desgastando la presencia del Espíritu evangelizador, que va diluyendo su 
fuerza carismática ante el avance de la organización, de la planificación y de la burocratización. Entonces los apóstoles se convierten en funcionarios y los evangelizadores se transforman en empleados. La mística se debilita y se moraliza sin desprenderse demasiado de los intereses particulares. La cruz evangélica y la resurrección pascual quedan acomodadas al egoísmo estructural y a la comodidad individual. Se va perdiendo paulatinamente la potencia del Espíritu.

Por ello, la propuesta para la Iglesia, para la pastoral, es la propuesta desde la pobreza en los medios, en los destinatarios preferenciales, en las presencias institucionales. Sin radicalidad en la presencia cristiana no se despierta el entusiasmo del seguimiento de Cristo y del anuncio de su Evangelio, por más técnicas que se tengan. Por ello, el título de las presentes reflexiones: "¿Vamos a lo central!"

La pobreza de la encarnación no es solo de tipo económico, sino que se asienta en la pobreza y desprendimiento personal, que implica una inmensa confianza en la presencia amorosa del Padre Dios que hace a sus seguidores más libres en el camino del amor y del servicio. Cristo y su Espíritu no son simplemente enunciados ideológicos, sino que tienen connotaciones personales y comunitarias vivificantes, que dan sentido a la urgencia del Reino, a la utopía de la nueva creación y a la denuncia de las limitaciones históricas que deshumanizan la situación actual. La pobreza evangélica plantea un gran vaciamiento del propio ego en sus aspectos individualistas, a fin de dar espacio al Espíritu del Señor que lleva a una confianza mayor en la presencia de Dios en la historia, en las personas, en los acontecimientos, abriendo la vida a la providencia que nunca abandona a sus hijos. Esta pobreza no exonera de los esfuerzos y fatigas personales y comunitarias, que siempre se reorientan en función del Reino, y no de las instituciones particulares, por más piadosas que aparezcan. Encarnar a Cristo hoy no se reduce solo a los aspectos celebrativo - litúrgicos, ni a los enunciados teológicos de nuevo cuño. Precisamente es la vida de los seguidores de Cristo la que debe encarnar la presencia del Señor hoy a través de estilos de vida más evangélicos, sencillos, fraternos, de mucha mayor transparencia. Menos estructuras y más vida, menos organización y más profecía es la perspectiva que las gentes de esta generación pueden ir comprendiendo con una cierta aceptación y simpatía. Por ello, reiteramos que es indispensable rescatar "lo central" de la vida cristiana. 


\section{Dimensión de espiritualidad}

Una segunda vertiente de vida creyente para proponer una nueva manera de ser Iglesia de Cristo gira alrededor de la vida en el Espíritu por parte de los cristianos. Seguramente la onda secularizadora de laicización del cristianismo ha dejado en segundo plano este aspecto indispensable de la vida cristiana. En efecto, Jesús nos dice que sin Él no podemos hacer nada, y se refiere precisamente a este aspecto que plasma la aceptación cada vez más interiorizada de Cristo, de su Espíritu, del Evangelio, del Reino, que se abre a todas las realidades donde está inmersa la personalidad creyente. Los cristianos a medida que vamos madurando en Cristo estamos llamados a revivir el amor de Jesús en todas sus implicaciones. Por ello, la vida en el Espíritu no se identifica de manera total con el proceso de toma de conciencia ante las realidades personales y sociales (concienciación); tampoco se reduce a la enseñanza de nuevos paradigmas teológicos en la interpretación del mensaje cristiano (enseñanza magistral); ni siquiera es agotada por las propuestas pastorales o políticas de los novísimos planes de acción (planificación).

La vida en Cristo sin duda puede coincidir en forma parcial con planteamientos pastorales, sociológicos, educativos o políticos, pero no se identifica con ellos, sino que los rebasa ampliamente por su vinculación con la vida de los creyentes y sus opciones concretas. En efecto, la vida creyente asumida de manera vital se engarza con una participación en la presencia divina en la historia que envuelve elementos místicos, éticos y de visión de la vida que mientras más se acercan al Evangelio en la práctica de Jesús, más personas y libres hace a los cristianos. La vida de fe es una experiencia radical, específica, que no puede ser identificada con ninguna otra disciplina científica. Las ideologías del momento histórico pueden ayudar a aclarar contenidos de esta experiencia fundante. Pero en la medida en que se asume con seriedad y honestidad la vida de Cristo, los cristianos nos convertimos en una fuerza irresistible e insobornable. Con toda razón podemos afirmar que la espiritualidad cristiana no es de ningún modo un camino de alienación ante la sociedad y las personas, sino que permite vivir y actuar desde la perspectiva de Cristo en la historia, en las comunidades y en las relaciones interpersonales. Por ello, a ejemplo de Jesús, las personas de Espíritu no se dejan manipular por nadie, ni personas, ni sistemas, sino que son abier- 
tas y libres ante todas las propuestas que se hacen y se viven. Allí está la raíz de un auténtico profetismo cristiano, porque la libertad de Espíritu no tiene nada que perder ni con los gobiernos, ni con las autoridades, ni con el pueblo, ni con las jerarquías. Las estructuras no esclavizan a los cristianos de mística total, porque no están amarrados a nada ni a nadie. Esto resulta muy difícil para cualquier institución civil o religiosa, que está interdependiendo de muchas estructuras y niveles en la sociedad circundante.

Sin embargo, mientras no alcancemos a generar esta docilidad viva, audaz y alternativa que viene de Dios en su Espíritu, no alcanzaremos a responder adecuadamente a la voluntad de Dios como personas, comunidades e Iglesia en general. Para vivir esta óptica de espíritu, no podemos brindar a nuestra sociedad tan amante de planes y recetas, ninguna solución, sino invitar a sumergirse en la experiencia del Dios salvador, como la experimentaron María, los apóstoles, Moisés o Jeremías, por poner algunos ejemplos. Para muchas personas de esta generación, puede parecer una propuesta utópica, simplista, ingenua o acrítica, porque hacen el análisis desde parámetros racionales, estructurales, dialécticos holistas, o como queramos llamarlos. Sin embargo, el Evangelio hace la propuesta del Reino de salvación integral, a partir de experiencias de fuerte contenido espiritual, como lo reflejan las palabras de Jesús a los primeros discípulos, "vengan y lo verán" (Juan 1, 39). Cristo invita a compartir la vida, sus palabras, sus propuestas y expectativas, y ello genera paulatinamente un movimiento de libertad y de conciencia que tiene siempre un poder de transformación positiva a lo largo de la historia.

Desde esta experiencia de Dios en la historia se siguen caminos de radicalidad evangélica, de desprendimiento de sistemas y estructuras, de distancia profética ante lo ya establecido y muchas veces anquilosado. Efectivamente la libertad en Cristo forja cristianos que al tomar distancia de las situaciones ambiguas y de pecado, van entrando por un proceso de conversión a Dios y a los prójimos siguiendo el camino del Señor Jesús. Quedan cuestionadas todas esas modalidades de cambio "ab intra", desde adentro del mismo sistema globalizante, neoliberal y expoliador que se disfraza de "ayudas y planes para el desarrollo" para seguir abusando, dominando y enriqueciéndose a costa del margen de ganancia que generan los pobres de la tierra. La gran tarea consiste en “dejar a Dios que sea Dios" en la vida, de modo que se relativicen todos 
los demás proyectos y esquemas, ídolos y planificaciones que solamente ofrecen paliativos adormecedores a los pueblos dominados. Esta espiritualidad de conversión personal, comunitaria e histórica, tal como la encontramos en el Evangelio es la gran levadura que puede ayudar a la Iglesia a ir superando sus crisis. No se trata de entrar en confrontaciones estériles ni con la jerarquía, ni con la estructura eclesiástica establecida, pues ello provocaría el desperdicio de mucha energía que se necesita para ser más fieles al llamado del Espíritu del Señor. Lo importante va en la línea del seguimiento de Cristo, que convoca con su ejemplo y su palabra a una generosidad y creatividad mayor a los cristianos para liberarnos de muchas tareas y desafíos secundarios, a fin de propender hacia la vivencia y el anuncio del Evangelio en nuestro mundo.

\section{Dimensión de comunidad}

A semejanza de Jesús, el seguimiento del Evangelio implica romper los muros del individualismo para construir comunidades que se autoidentifiquen por su mística cristiana y que tengan la apertura misionera ante el resto de la Iglesia y en la sociedad pluralista. En la actuación de Cristo encontramos que Él formó la comunidad de apóstoles y más ampliamente de discípulos para que sean la semilla que lleve adelante el proyecto del Reino de Dios. Fue el inicio de la Iglesia que se extendió progresivamente por los diversos pueblos y culturas del Imperio.

Y desde entonces la vivencia comunitaria del cristianismo se ha mantenido de diversas maneras y con diversos acentos derivando sea en comunidades religiosas como en comunidades y movimientos laicales. El pluralismo de presencias y formas ha sido una eclosión del Espíritu que sopla donde quiere y como quiere. Como toda modalidad eclesial, que tiene de humano y de divino, ha tenido sus aciertos y sus límites. En algunos se han dado más formas espiritualistas y en otros más acentos seculares. Sin embargo, es verdad que las explicaciones, los documentos, las explicitaciones de las vivencias concretas, han ido mucho más allá que las realizaciones prácticas que han sido con frecuencia más humildes y sencillas.

En este cambio de coyunturas, que comporta una crisis epocal, el cristianismo se siente interpelado por la necesidad de nuevas respuestas comunitarias, que superen las cerrazones sectarias y que amplíen los 
compromisos en función del Reino, como signos de una Iglesia que sigue presente en las nuevas situaciones socio-históricas. La asimilación de una espiritualidad abierta a la comunidad es un desafío siempre presente que pide ese difícil camino entre persona y grupo a fin de que interactúen con una gran transparencia de vida en todos los aspectos. Pero la comunidad deberá tener como referente las condiciones estructurales de la sociedad en que se encuentra inmersa, a fin de alcanzar compromisos que fomenten caminos de libertad fraterna y de justicia real. La perspectiva será la de Cristo, donde las ciencias sociales pueden tener un papel iluminador, pero no determinante, a la hora de las opciones concretas del amor cristiano. Es decir, el amor cristiano tiene un papel crítico aun frente a los instrumentos de análisis de la realidad, para buscar en la práctica concreta los recorridos más humanizantes y evangelizadores en su relación con el mundo circundante. Por desgracia la experiencia pastoral y apostólica ha hecho ver que muchos agentes de pastoral, activistas cristianos, se fueron diluyendo a la luz del discurso, de la fraseología y de la ideología del último momento, y quedaron vacíos de mística cristiana; no llama la atención que tarde o temprano hayan abandonado la militancia como cristianos. Fueron los casos en que la ideología animó opciones que no estaban arraigadas con la centralidad de la persona, que es lo que plantea, por el contrario, siempre una auténtica vivencia cristiana en el Espíritu.

Dentro de este caminar creyente comunitario, a medida que maduran la vida y el compromiso cristianos, se van venciendo las actitudes individualistas de arribismos económicos, culturales o sociales, de modo que se superan las aspiraciones por intereses particulares, que han arruinado numerosos movimientos, grupos y organizaciones eclesiales y socio-políticas. La vivencia cristiana, cuando se la experimenta con intensidad, permite que el Señor arraigue con su presencia en los límites más significativos de las personas, donde se juegan la misma vida y la misma muerte. Desde las opciones fuera del cristianismo, han surgido personas y grupos que asumen con integridad y coherencia los valores de la transformación radical, viviendo la existencia con admirable entereza y totalidad. En la Iglesia, hay muchísimos cristianos que han sabido asumir el amor cristiano dentro de su radicalidad vital.

Finalmente, una última observación sobre la comunitariedad, la podemos hacer al plantear como Jesús, comunidades abiertas a la sociedad, a las culturas, a los otros. De hecho, el gran peligro de las comunidades consiste en cerrarse en una autoidentificación engañosa y egoísta, 
donde para sentirse más seguros, se encierran ante las propuestas que vienen de afuera, construyendo todo un mundo simbólico, celebrativo, cultural y organizativo que se estructura casi paralelo al mundo que les rodea. Entonces las comunidades tienen mucho de secta, grupo separado, personas iniciadas, que no alcanzan a interrelacionarse con más fluidez con el resto de las personas que quedan "profanas" a ese mundo de "iluminados".

$\mathrm{El}$ aspecto misionero del Evangelio que plantea ir "desarmados" a las misiones para ser recibidos y recibir de los otros es muy ilustrativo. En cambio, cuando los misioneros van con todo el bagaje de "sus verdades", "sus esquemas" y "sus métodos", llegan más como colonizadores de ese nuevo mundo cultural, antes que servidores del Evangelio, fermento de todas las vidas y culturas. No se trata de abandonar el espíritu cristiano, pero sí de buscar sus realizaciones concretas, según las condiciones del pueblo que es visitado. ¿Qué importante es que las comunidades caminen con la gente, y no sobre la gente!

En la medida en que la vida cristiana logre brindar signos positivos de lo que es experimentar y practicar el amor cristiano, sea como personas como comunidades, entonces, podemos esperar buenas noticias para la Iglesia, para la sociedad, para las mayorías. No se trata de hacer un nuevo camino de elaboración especulativa, sino de intentar nuevas experiencias concretas y vividas. Aquí hay un gran desafío para el futuro de la Iglesia y del cristianismo.

\section{La Iglesia como signo y servidora del Reino}

Hagamos aún alguna consideración que la teología repite pacíficamente, pero que la práctica pastoral lo olvida con mucha frecuencia. Efectivamente la Iglesia entendida como pueblo de Dios, como comunidad de creyentes o como comunidad de comunidades, siempre tiene un papel de "pequeño rebaño", es decir, una humilde presencia sacramental en cuanto signo de la salvación de Cristo a lo largo de la historia. El ser de la Iglesia en cuanto espíritu, carismas, organización se debe mover siempre en función del crecimiento del Reino de Dios, que es el plan pastoral fundamental que Jesús vino a inaugurar. La Iglesia no es el Reino; cuando en la historia pretendió agotar el Reino, fue enseguida empobreciendo y achicando su horizonte de comprensión y de acción en 
el mundo. El Reino es más amplio, y está animado por el Espíritu de Jesús que actúa en las más variadas realidades y espacios de una manera que no alcanzamos a captar en su globalidad con nuestra limitada comprensión.

La Iglesia tiene el papel de mediación, de signo, de indicación de los caminos del Reino de Dios en la historia humana. Por este motivo, la Iglesia no puede pretender jamás agotar todos los aspectos de la salvación de Dios en el mundo, porque el Señor de la historia actúa con mucha mayor amplitud que la Iglesia, santa y pecadora. La Iglesia simplemente como "luz de las gentes" indica caminos, ilumina la vida, plantea el sentido y el valor de la vida humana.

Sin embargo, por más historicidad que tenga la Iglesia en este mundo, no tiene como misión fundamental arreglar todos los problemas personales, familiares, comunitarios o sociales de la historia. Como Jesús, la Iglesia plantea acciones que son signos de la presencia y de la acción de la salvación de Dios en el mundo. De hecho, Cristo no curó a todos los leprosos de Israel, ni salvó a todas las prostitutas de la época, ni liberó a todos los pobres de la opresión. Él puso signos que puedan ser comprendidos y asimilados desde la fe de las gentes, para señalar que el Reino de Dios está llegando. Hace poco un funcionario de las Naciones Unidas indicaba que la Madre Teresa de Calcuta no resolvía el problema de los 840 millones de personas que padecen de hambre en el mundo. Y es verdad, porque ese no es el papel específico de la Iglesia, sino que pertenece a los Estados y a la sociedad en general; la Iglesia pone simplemente signos de salvación.

Y precisamente aquí encontramos una de las grandes ambigüedades de nuestra pastoral actual, en el sentido de que olvidamos nuestro papel de signos, y pretendemos abarcar en su mayor amplitud los problemas que nos rodean, sea educativos, culturales, organizativos, sociales, políticos, etc. Esta situación de apertura tan vasta hace que la pastoral de la Iglesia pretenda convertirse en solución subsidiaria a los problemas que el Estado democrático neoliberal no alcanza a resolver. Y ello a su vez, hace que el Estado utilice, en lo que pueda, los servicios de la Iglesia para "parchar" sus deficiencias, manipulando la voluntad de servicio de los cristianos activos. Por otra parte, en la solución de muchos problemas los organismos eclesiales se unen a los gobiernos de turno y organizaciones nacionales o extranjeras en el afán de conseguir recursos económicos que financien el frenesí de actividades e instituciones. Con 
ello, la Iglesia pierde su libertad de acción, se deja condicionar por los subsidios que recibe y se abre a un abanico de actividades que muchas veces le llevan a olvidar su tarea central de evangelizar. Se confunde muchas veces evangelización con acciones de promoción, se deja en la penumbra el llamado cristiano a la conversión desde la óptica de la fe para diluirse en cursos de formación de nuevos contenidos alternativos, y entonces no se pone el "vino nuevo" en "vasijas nuevas", sino que desembocamos en una adulteración, o del "vino" (el Espíritu y el mensaje) o de las "vasijas" (los agentes de pastoral y los medios). La Iglesia necesita volver a encontrar los caminos fundacionales para reelaborar su marcha hoy, abandonando muchos elementos que se han superpuesto en esta hora de la historia al trabajo primigenio y central que nos dejó Cristo Jesús. Cuántas superestructuras se han ido acumulando, como el polvo, sobre la Iglesia fundada por Cristo, es cuestión que debe pasar por un sincero examen de conciencia eclesial. El llamado de Jesús sigue siendo imperioso para que nos extendamos por toda la Tierra, pero con la simplicidad de medios, con la pobreza de presencias y con la autenticidad de la vida. El poder entendido como servicio desde los últimos lugares lleva a la revisión de mucho ejercicio del poder actuado desde las cumbres de muchas instituciones que se presentan como Iglesia. Mientras no acometamos este camino arduo y espinoso, la historia en su complejidad, cambios y crisis irá desmantelando paulatina y progresivamente el andamiaje eclesial en lo que no tiene asidero del Espíritu. Precisamente este es uno de los grandes signos de los tiempos para nuestra Iglesia hoy.

\section{Cristianos militantes}

Tanto en la vertiente eclesial como en la perspectiva secular, como Iglesia necesitamos el surgimiento y el apoyo de numerosos creyentes que deseen arriesgarse verdaderamente en función de una Iglesia proyectada al servicio del Reino, y no replegada en la defensa de sus instituciones. Recordemos que la Iglesia no es la sinagoga judía o solo lugar de oración, sino que es un pueblo que se abre a dimensiones amplias para influir como levadura en el mundo, en la sociedad en que vivimos. Los cristianos activos tenemos el llamado para ser luz y sal en la tierra, no solamente en la Iglesia hacia adentro. Desde nuestra pequeñez, el 
Espíritu pretende animar diversos carismas y funciones, que tienen la misión de servir al bien común, y no solo al grupo de iniciados en la religión. Más allá que salvar la pureza del depósito de la fe, o la claridad meridiana de verdades teóricas, los cristianos tenemos el llamado de Jesús para llevar a la práctica los mandatos del amor a Dios y a los hermanos. Sin estar obsesionados por la eficacia político-social de transformación, que la presente coyuntura no ofrece a corto plazo, los cristianos, la Iglesia, tenemos la urgencia de poner en muchas partes signos de salvación, de libertad, de fraternidad, de solidaridad, que son indicaciones de que el Reino de Dios está entre nosotros. Esta apertura social se arraiga en la conversión sincera y profunda de la vida personal, lo que se llama la "conversión del corazón" o el cultivo diáfano de una recia vida espiritual.

No sabemos si por pudor o por convicción, se dio tanto énfasis en estos últimos tiempos al compromiso, a la praxis de transformación, a la eficacia social, que se sobreentendió que ya los apóstoles tenían la experiencia y la vivencia del Espíritu del Señor en sus vidas. Y este supuesto, fue testigo de muchos quiebres en la personalidad de tantos evangelizadores, maestros y profetas de los últimos tiempos, que parecían tan radicales, pero que no lograron perseverar hasta el final. Puede ser que las nuevas opciones que tomaron hayan sido más evangélicas y radicales; no nos toca juzgar sobre las motivaciones e intenciones de cada uno. Sin embargo, la militancia explícita como agentes de pastoral, sacerdotes, religiosos (as) consagrados (as), se diluyó dentro de coyunturas eclesiales y sociales determinadas. También muchos laicos (as) comprometidos con la Iglesia y la sociedad, "echaron la toalla" y pasaron a engrosar, en el mejor de los casos, la pertenencia a diversos grupos de ONGs y Fundaciones con alcances limitados y hasta ambiguos en el compromiso socio-histórico. Cada cristiano que responda a su conciencia y ante la historia por las opciones concretas que ha asumido.

Si hay algo que falta al cuerpo eclesial en nuestros tiempos es la profecía que intuye los caminos del Señor en la historia más allá de las realizaciones pragmáticas y de corto plazo que muchas veces se realizan con poca esperanza. Mucha gente quedó desilusionada por la involución histórica que dio la sociedad y la Iglesia en estas últimas décadas, y ya no quiere saber nada. Sin embargo, consideramos que los desafíos están planteados, que el Reino sigue despuntando, que el Espíritu continúa con su acción constante, y espera más colaboradores para que se reorganice 
una Iglesia más comunitaria, más coherente en sus planteamientos de fe, más libre ante los condicionamientos del ambiente. Antes que sumergirnos en un activismo irreflexivo o en una depresión quejumbrosa estéril, necesitamos intuir las exigencias del Señor hoy, potenciar y explicitar más la vida del Espíritu en la existencia y en la práctica de los cristianos hoy, comprender y vivir más auténticamente el compromiso real desde los pobres, fortalecer las convicciones y vivencias de creyentes que no claudicamos ante la mediocridad de la sociedad. Puede ser que disminuya el número de los cristianos militantes, pero seguramente crecerá la intensidad de la mística y del compromiso, manifestando un perfil de creyentes que no se reducen a promotores sociales, antropólogos o peritos en cualquier otra rama de las ciencias humanas. Esta especialización puede ayudar, en la medida en que la personalidad cristiana esté definida vitalmente. No se trata de revivir el viejo esquema dualista de natural-sobrenatural, sino de explicitar dentro de la unitariedad de la experiencia cristiana el renacimiento "en espíritu y en verdad", que es la fuente discrecional para valorar y orientar el compromiso de los cristianos que no se diluyen en una ambigua secularización que en el fondo ahoga desde los elementos históricos la presencia explícita del Espíritu del Señor. Tampoco se trata de caer en misticismos piadosos y ahistóricos que se mueven en el plano de la emoción religiosa intrascendente. Sin embargo, a fuerza de ser justos con lo que plantea el Evangelio, es indispensable la maduración de una mística cristiana explícita que se abre a las diversas dimensiones de la vida cotidiana y del compromiso histórico.

En medio de la multiplicidad de propuestas que siembra el ambiente de la Iglesia y de la sociedad, necesitamos "con temor y con temblor", sin posiciones autosuficientes, volver a retomar los caminos del cristianismo hoy, inspirándonos en los orígenes de la vida cristiana, y en las líneas más preclaras y fecundas de la vida de la Iglesia en la historia. Allí encontramos un venero riquísimo para meditar, interiorizar y practicar la experiencia cristiana que hoy la Iglesia necesita antes que otra cosa. Ojalá se prioricen estos caminos fundamentales e indispensables.

\section{Creyentes más sensibles al Espíritu}

Estos caminos alternativos del Espíritu en la Iglesia y en la historia en general, se alimentarán con cristianos de nueva sensibilidad, que 
den pasos concretos, prácticos para ir abriendo caminos más acordes con el Reino que se anuncia en primer lugar a los pobres. Este renovado proceso de sensibilización ante el llamado de Dios hoy, se alimenta con la oración sentida y perseverante que garantice la contemplación del Invisible en la espesa trama de la historia que se vive. Estos cristianos de nueva estampa tienen la animación del Espíritu que les brinda la perspectiva original que permite detectar a Dios y a sus llamadas en las situaciones históricas más apremiantes, más necesarias del momento. Con toda razón, el apóstol Pablo pone de relieve la fuerza y la novedad del Espíritu de Dios, que muchos consideran una locura y una tontería. Escribiendo a los cristianos de Corinto, afirma: "Y nosotros no hemos recibido el espíritu del mundo, sino el Espíritu que viene de Dios, y por él entendemos lo que Dios, en su bondad, hizo por nosotros. Esto, no lo conversamos con palabras aprendidas, ni como enseñanza humana. Más bien, lo decimos como el Espíritu nos lo enseñó, hablando de las cosas espirituales a los que son hombres espirituales. El hombre, con su propia inteligencia, no capta las cosas del Espíritu. Para él son locuras. No las puede entender porque para eso se necesita un criterio espiritual" (1 Corintios 2, 12-14). La experiencia de este hombre espiritual como Pablo es tremendamente aleccionadora, a fin de ratificar este camino del Señor en el hoy de la historia. Este salto cualitativo, podríamos decir, en la sociedad y en la Iglesia nos reanima en la esperanza para comprender los nuevos tiempos que van a ir despuntando a pesar de la dura crisis que padecemos. En la medida en que entremos por esta "puerta angosta" pero gratificante del amor cristiano, vamos a ir encontrando los caminos de maduración de la vida cristiana en todas partes. Seguramente nos vamos a encontrar con la aparición multiforme de nuevos apóstoles que toquen fibras muy sensibles de la época que vivimos, y que despierten entusiasmo, respuesta y colaboración. Hay muchas energías positivas que están latentes en la historia, y que requieren de personas y de grupos que las detecten y las dinamicen con la visión del mismo Dios. Por ello, una contemplación encarnada, cercana a la realidad, sobre todo desde los que más necesitan, suministra la visión y la energía suficiente para desencadenar nuevos procesos de anuncio del Evangelio y de experiencia de salvación integral.

Pero no estamos resucitando un cristianismo liberal hecho por héroes solitarios, sino que se trata de que animar corrientes del Espíritu en la historia, donde unos cristianos llaman a otros, unos grupos entu- 
siasman a los de más allá, de modo que se vayan generando, desde la pobreza y sencillez, caminos de libertad y de justicia, de solidaridad y de veracidad. No son procesos fáciles, puesto que despiertan en seguida suspicacias, reacciones oficiales contrarias, recelos infundados. Pero la constancia y la coherencia de las comunidades cristianas permitirán que el amor fraterno sea un signo distintivo de la autenticidad de las propuestas prácticas que se van gestando. Esta inspiración carismática deberá estar atenta para evitar formas de institucionalización paralizante y opresiva, que llevarían al traste y a la disminución del empuje de estas energías libertarias renovadoras del pueblo y de la sociedad. Es muy importante que los cristianos estemos en contacto cercano con la realidad del pueblo, que revivamos los signos del Señor en las coyunturas históricas, y que fortalezcamos siempre la dimensión contemplativa, espiritual, de los apóstoles. Hay que dejar bien claro ante la sociedad y la Iglesia que no se está buscando el poder, ni la acumulación egoísta, porque el poder evangélico va en la perspectiva del servicio del amor y el dinero es simplemente un medio que se debe compartir con los hermanos evitando toda estructura que aleje de los destinatarios.

Laicos, religiosos, sacerdotes, jerarquía y pueblo, podemos hacer opciones concretas de este amor cristiano de signo eclesial, que hay que alimentarlo en las altas temperaturas del Espíritu de vida, para que no se diluya en la vulgaridad de la repetición, en la frialdad de la estructura, y en el anonimato de la Ley. Solo se necesitan cristianos que deseen hacer este paso de riesgo, de conversión, de pérdida de estatus social a los ojos de muchos. En la historia, la Iglesia ha sido testigo de muchos creyentes que arriesgaron todo, pasaron por el riesgo de la persecución y de la calumnia, y que se convirtieron en "modelos del rebaño". Su inspiración originaria del Espíritu comenzó a detenerse y a naufragar cuando sus sucesores quisieron plasmar el carisma en escrito, organización y estabilidad. Y desde allí comenzó el declive.

No hablamos de crear nuevos institutos de vida religiosa, sino de sensibilizar a los cristianos que deseen hacer opciones más maduras, para que entren por los caminos y por el "bello riesgo" del amor en su sentido más radical. Se trata de reaccionar a los caminos tan racionalizados de una evangelización toda planificada, y tan inútil. Más bien, hay que apelar a la vida, a los carismas, a las personas más desprendidas, a quienes tienen más sensibilidad ante Dios en la vida y en la historia. Y desde allí, hay que ir abriendo trochas para que la Palabra llegue a otros. 
No se esperen resultados espectaculares, sino lo que el Espíritu permita que se dé: "muchos son los llamados, pocos los escogidos", nos recuerda Jesús. Sin embargo, los resultados más modestos serán seguramente más verdaderos, superando la ilusión de considerar que la Iglesia cuenta con "masas cristianas". La actitud de desprendimiento evangélico de "nada para mî", sino "todo para Dios y para los hermanos" será el gran testimonio que indique las motivaciones que mueven a los nuevos apóstoles de hoy. Sin embargo, esta actitud evangélica no puede ser solamente de palabras, sino con la práctica coherente de vida que se traduzca en la manera de actuar.

Cuando Jesús es asimilado vitalmente por los cristianos apóstoles, muchas cosas comienzan a cambiar en la relación con la familia, con el trabajo, con las amistades, con el dinero, con las comodidades. La vida en Cristo reanima las mejores fuerzas de cada uno, y hace arder el corazón para vivir, anunciar y construir signos del Reino de Dios. Esta es la mística auténtica que reanima el caminar cristiano, puede renovar la Iglesia, y se convierte en un signo de transformación en el mundo. Espacios sí hay para trabajar en esta perspectiva de Evangelio; quizás lo que más falta son los cristianos que se decidan a arriesgarse por este camino venciendo las inseguridades, oposiciones y riesgos. Precisamente es la lógica del gran amor por la "piedra preciosa" que lleva a abandonar todo el resto, con tal de conseguir ese magnífico amor, capaz de dar plenitud a la vida, a pesar de las carencias económicas y de reconocimiento público. Cuando nos damos cuenta que la vida y su autoestima, dependen de la propia manera de mirar y de actuar en la realidad, entonces relativizamos mucho la presión social, la imagen que brindamos a los demás y las alabanzas o vituperios que puedan proferirse. Cristo actuó así, con gran independencia ante sus coetáneos, sea de la condición social que fueren. Pero para llegar a esta gran madurez humana y creyente, se necesita un camino de gran conversión al gran amor de la vida, Dios y su Reino. Personas, comunidades y grupos con seguridad están buscando estos caminos de radicalidad cristiana para dinamizar nuevas energías en el cuerpo de la Iglesia y de la sociedad. Hay que comenzar a buscar su surgimiento, como lo hizo Jesús. 


\section{Ruptura para crecer en la caridad}

Todo crecimiento y cambio requiere una dosis de sacrificio, de donación, de tomar distancias. En la Iglesia y en la sociedad va a darse este fenómeno en los procesos de maduración y de transformación. Ya lo experimentó el mismo Jesús en sus confrontaciones ante el servilismo esclavizante y devoto de los seguidores de la ley de Moisés. Así lo vivieron los apóstoles en la primera expansión del cristianismo. Así lo han vivido muchos cristianos ejemplares reconocidos como santos en las tensiones entre lo ya establecido y lo que se va proponiendo. Muchas veces formas religiosas con consecuencias sociopolíticas que fueron calificadas como "heréticas" tuvieron también gérmenes de transformación positiva que no lograron conjugarse históricamente con el cristianismo ya establecido, por lo que llegaron a rupturas irreconciliables que hoy debemos lamentar. Pero ello no quita que, el surgimiento de una nueva calidad del amor cristiano, en nuevas situaciones y contextos, demandará nuevas respuestas que no siempre serán comprendidas por los detentadores de las prácticas oficiales y tradicionales. Sin entrar en confrontaciones de rompimiento con la jerarquía y con el resto del pueblo de Dios, "con la astucia de la serpiente y con la sencillez de la paloma", como lo propone el mismo Señor, se trata de ir buscando los caminos que permitan renacer "en Espíritu y en verdad". Con el riesgo de equivocarse, hay que avanzar con la mentalidad y con el corazón de Cristo, y con la perspicacia de la inteligencia y de la voluntad vigilantes, para ir respondiendo a las situaciones concretas que emergen de la crisis generalizada que estamos viviendo. Ante las dificultades crecientes para anunciar y vivir el cristianismo, se necesitan respuestas creativas y generosas, donde los evangelizadores paguen con su propia persona, de tal manera que se garantice la autenticidad de la propuesta. Ya lo advirtió el Señor cuando dijo: "Acuérdense de lo que les dije: el servidor no es más que su patrón. Me persiguieron a mí, también los perseguirán a ustedes. No hicieron caso de mi enseñanza, tampoco harán caso de la de ustedes" (Juan 15, 20). Precisamente el desconocimiento y aun el desprecio de los agentes de procesos alternativos, es uno de los pasos pascuales que exige este caminar. Efectivamente recrear respuestas nuevas de anuncio del Evangelio en los nuevos escenarios que vivimos, volver a retomar los últimos lugares y ser solidarios con los que padecen a consecuencia de los dominadores del imperio de turno, plantea un aleja- 
miento de las formas establecidas de la acción eclesial imperante, lo que puede provocar tensiones explicables. Sin embargo, allí es donde se mide el temple de los nuevos agentes de cambio. Muchos teólogos del Concilio Vaticano II habían sido silenciados en la época preconciliar; muchos santos debieron abrir paso al carisma recibido, sorteando tensiones y dificultades con sus cohermanos de religión o con sus obispos; muchas voces disidentes ante las ideologías dominantes fueron acalladas o menospreciadas por las así etiquetadas derechas o izquierdas del momento.

Como para recordar algunos casos testimoniales, evocamos la figura de San Francisco que no accedió al sacerdocio de su época, de modo que fue más libre para actuar desde una pobreza radical; Santa Teresa de Ávila y San Juan de la Cruz pasaron por muchas penalidades en el afán de dar una mayor autenticidad a la Orden del Carmelo; San Juan Bosco se expuso a la inseguridad de la pobreza rehusando una cómoda capellanía de niñas a fin de consagrarse a la misión de servir a la juventud pobre y abandonada desde los arrabales de Turín. Y los casos podrían multiplicarse de manera muy abundante, de modo que el desviarse de la normalidad rutinaria de la mayoría es el costo que deben pagar muchos creyentes y no creyentes renovadores a fin de inaugurar las sendas que el Espíritu está sugiriendo. Puesto que el Espíritu no tiene lógicas cerradas ni rutinas establecidas, puede sorprendernos gratamente de maneras insospechadas. Es cuestión de mantenernos en actitud vigilante, creyente, flexible.

Por esto afirmamos que la emergencia de nuevos caminos en la sociedad y en la Iglesia pasará por el martirio real o la exclusión cultural y política de los agentes de transformación. El precio de la libertad y del amor se paga con la vida, ya que como dice la Escritura "no hay salvación, sin efusión de sangre". Solamente las personalidades y grupos que estén asentados sobre rocas firmes de convicción, de fe, de amor, podrán resistir al embate de las oposiciones. Sin duda, es muy halagador hablar de conversión y de transformación, sin ser tocados un ápice en los propios intereses de la vida privada. Es tan fácil construirse un nido de seguridad, pobreza y fe hecho a la propia medida. Pero no ha sido este el ejemplo recibido. La Escritura dice con toda claridad de los primeros cristianos: "Recuerden esos primeros tiempos en que ustedes acababan de ser iluminados. Tuvieron que soportar grandes sufrimientos que les vinieron a asaltar. Fueron públicamente expuestos a humillaciones y 
pruebas, y tuvieron que participar del sufrimiento de otros que fueron tratados de igual manera. En verdad ustedes se hicieron solidarios de los que iban a la cárcel; a ustedes les quitaron sus bienes y lo aceptaron gozosos, sabiendo que estaban adquiriendo una riqueza mejor y más duradera" (Hebreos 10, 32-35). ¿De dónde sacamos los cristianos esta fortaleza y este temple de ánimo, si no es de la presencia plenificante de Cristo Jesús? No es una alienación, ni una aberración, para los que realmente se dejan conducir por los caminos del Señor. Esta fortaleza brota de la experiencia salvadora de Jesús, que desde el bautismo va alimentando la vida para las grandes acciones. Lo importante es actuar en conciencia y de manera coherente, de modo que se vaya adquiriendo siempre más la libertad ante las leyes, las organizaciones, el reconocimiento social, la familia, las autoridades, la misma Iglesia tal como está establecida. El amor cristiano sobreabunda y permite asumir sin dramas ni nostalgias las rupturas que se deben hacer. Pero la locura de la cruz de Cristo no puede ser domesticada por la sensatez de una religión ya establecida que va apagando la profecía y las posibilidades de alternativas concretas. Justamente a los cristianos más sensibles al llamado de Cristo en la historia se les está pidiendo amar a la Iglesia, pero irla abriendo siempre más a los requerimientos del Espíritu hoy. Con la Iglesia, pero caminando más allá en profundidad y en estilo, es el llamado misionero que el amor de Cristo sigue haciendo a nuestras generaciones. Y en la medida en que vaciamos más nuestro Yo egocéntrico, los procesos se pueden ir dando con más veracidad. Pero si no se dan simultáneamente los pasos para la conversión personal, entonces la conversión eclesial y social corre el serio riesgo de convertirse en una moda pasajera, superficial y sin trascendencia; a las primeras pruebas sucumbirá, como lo hemos visto en numerosas oportunidades, porque el poder da vértigos, y el dinero corrompe, cuando no hay personas y grupos libres en toda su amplitud. Por consiguiente, apelamos al mismo Evangelio en su más genuina práctica, al amor en su más profunda vivencia y a la libertad en su más radical expresión como caminos para mirar con esperanza un futuro más halagüeño para todos. Oración, Palabra, Sacramentos, Comunidad se engarzan admirablemente en este programa de vida y de acción que irá emergiendo siempre más con nuestra colaboración, o a pesar de nuestra omisión. 


\section{¿Estamos soñando?}

Muchos podrán decir que estamos soñando en una Iglesia irrealizable, que no es posible barrer con más de veinte siglos de cristianismo, o que estamos planteando un "angelismo" irrelevante en estos tiempos de eficacia y de compromisos históricos transformadores. Simplemente pensamos que si no miramos hacia el futuro con los ojos del Espíritu y con los pies en la tierra, nuestra Iglesia seguirá dando pasos acelerados hacia atrás en la historia, condicionada por las situaciones cambiantes de los tiempos y de las épocas. No se trata de imponer a nadie a la fuerza un llamado. Jesús no obligó a nadie a abandonar el judaísmo, sino que sencillamente propuso un ejemplo de vida y anunció un mensaje salvador. En su época, Jesús pudo aparecer como un soñador trasnochado con planteamientos utópicos, entendidos en su sentido negativo de irrealizables. Efectivamente, vivir la fraternidad dentro de una sociedad violenta y estratificada de manera tan rígida, habrá sido sin duda una propuesta chocante y considerada por muchos como una simple quimera. Sin embargo, su vida, su Palabra, su Espíritu siguen vivos y alientan siempre a seguidores de todas las generaciones para que asuman la posta y continúen su caminar. Muchos amoldan el amor cristiano a sus intereses mezquinos, y elaboran una mezcla sincrética de cristianismo unido a otros elementos de seguridad, de dominación, de placer, de fuga, etc. Pero siempre hay cristianos más sensibles que alcanzan a captar los llamados del Señor en las diferentes épocas y que van abriendo con grupos y comunidades senderos más purificados, auténticos, en fin, más evangélicos.

Pero resulta que si no miramos como Jesús los caminos del Reino desde ahora hacia el futuro, vamos siendo triturados por la eficacia utilitarista de los hijos de este mundo, que pretenden manejar todo según su propio beneficio. Y manejan aún las Iglesias y las religiones, en función de sus proyectos generalmente egoístas, absorbentes, y dominadores. Por ello, es tan importante que los cristianos sigamos en la práctica el mandato de Jesús, que invita a "estar en el mundo, sin ser del mundo", que plantea una tensión fecunda para mirar siempre más allá de lo que ve la mayoría de las personas. Con mucha razón se ha dicho, que "la Iglesia puede eliminar a los profetas, pero pierde el sentido de su historia", ya que son esas personalidades y grupos aquellos que vislumbran los caminos del Señor en la vida concreta de cada uno y de los pueblos. 
Y no se trata simplemente de hablar o de proclamar, sino de pagar con la propia persona, con el propio compromiso, que muchas veces padece el desprecio, la marginación, la exclusión por parte de aquellos que manejan los hilos de la historia en los pueblos y en las Iglesias. En fin de cuentas, se van confrontando en mayor o menor grado los proyectos de mantenimiento y de justificación, con los proyectos de transformación y de búsqueda. Muchas veces hay que ir optando entre la seguridad institucional o la inseguridad de la vida que sigue su curso. Los cambios pueden demorar más o menos tiempo, según las diversas situaciones internas y externas, personales y objetivas; pero es indispensable que aunque sea como una minoría aplastante, se mantenga vivo el fuego del Espíritu, la esperanza en una convivencia alternativa, la visión del mundo nuevo. Siempre los caminos alternativos de la vida en medio de la muerte, del Espíritu en medio de las instituciones, de los excluidos en medio de la dominación reinante, son trabas en el camino de quienes llevan el poder en su propio beneficio. Lo negativo reside en apagar la esperanza, en sofocar el Espíritu, en alinearse con los dominadores de siempre que dicen una cosa y hacen otra, que prometen cambios, pero mantienen fielmente la continuidad caduca y opresiva.

Con la resurrección de Cristo Jesús, la utopía se ha vuelto más cercana, el Reino está ya comenzando, el amor sigue vivo, los sueños son más plausibles, la nueva humanidad está ya en ciernes, la Iglesia guarda en sí los gérmenes alternativos de superación cualitativa. Tenemos la profunda convicción de que estamos más cercanos de una nueva aurora, de que van a ir surgiendo siempre más creyentes comprometidos con las reales transformaciones. Los cambios ilusorios de palabras, de planes, de estrategias, desde lo mismo, ya han probado su inutilidad y su vaciedad. En el fondo, nadie cree en ellos, por más que se los publicite y se los proponga. Muchos nuevos planteamientos encierran desgraciadamente mucho de lo viejo y caduco, y por ello, no tienen una salida exitosa. Seguramente nuevos apóstoles surgirán en diferentes partes, que irán ayudando a madurar un camino de mayor autenticidad, de más sencillez y de mayor vivencia cristiana. Cualquiera de nosotros puede ser uno de ellos, en la medida en que "dejemos que los muertos entierren a sus muertos", y no perdamos ya más tiempo a fin de ir en la búsqueda de los caminos siempre antiguos y siempre nuevos del genuino seguimiento de Cristo. 